\title{
THE SIGNIFICANCE OF DEATH-SCENE INVESTIGATION IN DETERMINING CAUSE AND CIRCUMSTANCES OF MEDICO- LEGAL DEATH
}

\author{
Corina Crisan* \\ "Vasile Goldiș" Western University of Arad, Romania, E-mail: corina73crisan@yahoo.com
}

(Received: June 2019; Accepted: August 2019; Published: November 2019)

\begin{abstract}
The article presents two cases of the Arad Medico-Legal Department illustrating just a part of the role of the forensic pathologist at the death scene but there are sufficient to fully justify the importance of this investigation as no example can comprise the complexity of problems and the particularity of each case, nor a statistic can be made. Both cases were found dead at home and forensically autopsied, but the two of them were distinct in terms of forensic pathologist's request death scene participation. In the first case, the autopsy did not find traumatic lesions, but revealed that the death was due to massive hemoptysis caused by cavernous tuberculosis with subsequent exsanguination, microscopically confirmed. The death was nonviolent. In the second case, the autopsy revealed findings of mechanical asphyxia due to neck compression, both macroscopically and microscopically. The death was violent. In both cases the forensic expert participation is required at the death-scene.

In the first case it allowed the correct interpretation of the traces of blood found on site, and in the second case, an onsite research would have properly helped for restoring the death's occurrence.

The scene investigation and autopsy provide, together, the basis for an accurate determination of cause and circumstances of death.
\end{abstract}

Keywords: death-scene, forensic pathologist, autopsy

\section{Introduction}

Crime-scene investigation is an integral component of many aspects of more general investigations. It can provide investigative leads, aid in the identification of suspect or victim, identify a modus operandi, establish the corpus delictus, and create linkages and associations among the victim, suspect, scene and evidence [8].

\footnotetext{
*Corresponding author: Corina Crişan. E-mail: corina73crisan@yahoo.com
} 
Crișan, C., (2019)

The significance of death-scene investigation in determining cause and circumstances of medico-legal death

A forensic pathology investigation is not merely a matter of autopsy performance, a series of steps comprises the totality of the investigation of witch omission weakens the investigation and conclusions of the forensic pathologist. Nonattendance at death scene is considered one of the classical mistakes in forensic pathology. [6]

Recommendation No. R (99) 3 of the Committee of Ministers to member states on the harmonisation of medico-legal autopsy rules specified general principles and examination of the body for death scene investigation. In case of obvious or suspected unnatural death, the physician who first attended the dead body should report the competent authorities, the latter deciding whether an examination should be carried out by a qualified medico-legal expert or by a physician familiar with medico-legal examination. Particularly in cases of homicide or suspicious death, medico-legal experts should be informed without delay and, where appropriate, go immediately to the place where the body is found and have immediate access there. In this respect, there should be an adequate structure of co-ordination among all persons involved and, in particular, among judicial bodies, medico-legal experts and police. The police in agreement with the medicolegal expert obtain identification of the body and other pertinent information from scene witnesses, including those who last saw the decedent alive, where available.

\section{Death-scene investigation of medicolegal death}

In Romanian legislation (Criminal Law Procedures - CPP) is stipulated that death scene investigation is carried out whenever there is suspicion about a person's death (art. $192 \mathrm{CPP}$ ). Is also specified that for elucidating the circumstances of death this investigation is conducted in the presence of a forensic pathologist when necessary (art. $194 \mathrm{CPP}$ ) and to ascertain if there are reasons to perform a forensic autopsy, the investigating authority may request the opinion of a forensic pathologist (art.185 CPP). It is an initial activity in the process of criminal investigation and is characterized by its urgent, mandatory and usually unrepeatable condition [7]. Thus the investigator has the liberty to include or not a forensic pathologist in the investigating team of death scene.

Although the medicolegal literature considers death scene investigation as an integrant part of forensic death investigation, the criminal procedure code has no regulations regarding this aspect referring only to situations when a forensic autopsy is compulsory. This leads to uneven judicial procedures in investigating a death with great regional differences. In National Institute of Legal Medicine Mina Minovici Bucharest (INML) there is a forensic pathologist always available for this investigation and is routine practice to attend to every death scene where a investigation is conducted and has attributions in selecting the medico-legal cases [1]. This is not the case in majority of medico-legal institutions especially in local

54 sciendo Journal of Legal Studies Volume 24 Issue 38/2019 ISSN 2457-9017; Online ISSN 2392-7054.

Web: publicatii.uvvg.ro/index.php/jls. Pages $53-62$ 
services. In Arad county (situated at the west border of the country, with a population of 471826 people), there was the practice to enroll the forensic pathologist in homicide or suspected homicide cases and traffic events with hit and run victims investigation. For the rest of the cases the presence of the coroner is not required on-site, neither for the selection of forensic cases neither for the participation in the investigation of medical- legal cases. Anyhow, in the interbelic period, we found in the forensic archive of Arad county that the forensic pathologist was present on site to recommend the forensic autopsy and had an active role in on-site investigation of violent deaths. We present from the archives of 1930 a forensic document entitled "medical-legal certificate" in which the forensic pathologist, after conducting an on-site research, was suggesting that a forensic autopsy is necessary (Fig. 4), and also we present a medical report that includes an outline of an on-site research conducted by the forensic pathologist to shooting crime (Fig. 5).

According to the legislation the police officers conducting the investigation have the ability to call a pathologist to the scene if considered needed in the investigation. As funds allocated to institutions who benefits from work of medicolegal services are frequently insufficient this cost are a burden and even in cases of murder or suspected murder there isn't a constant practice to call the forensic pathologist at the death scene. In recent years the forensic pathologist visit the death scene in a reduced number of cases. This influences both the selection of medico-legal cases (a number of 628 autopsies in 1990 that decreased to 473 in 2000, 405 in 2010, 397 in 2015 and 345 in 2018) and the quality of forensic death investigation, as evaluation and interpretation of traumatic injury and its causal relation with death without a forensic investigation is subjective and not only hazardous but also not recommended in the absence of objective, scientific evidence. In many cases the and autopsy performed after exhumation in litigious cases is unable to answers the questions by providing objective evidence due to postmortem decomposition.

In support we have chosen to present two different cases in with the forensic pathologist have an important role in death scene investigation for solving the case. First case is of a women 79 years of age who lived alone in her house. She was found death in the front yard, the body was clad with traces of blood on the clothes, face, arm and feet. (Fig.1) There was also trace of blood on the court aisle. Inside the house there was traces of blood on the floor from the bed to the exit door with shoe treads. There was also found a basin with large volume of blood cloth. At this stage the police officer investigating the case requested a medico-legal investigation. The external examination at the scene did not reveal traumatic lesions raising the hypothesis of pathological condition. The autopsy revealed massive hemoptysis as the source of externalized hemorrhage. Initially on gross 
Crișan, C., (2019)

The significance of death-scene investigation in determining cause and circumstances of medico-legal death

and microscopic examination was suspected the presence of metastatic melanoma. To confirm the diagnostic immunohistochemistry analysis was performed on lung and lymph node fragments. Imunohistochemical reactions were negative for cytokeratine, HMB 45 vimentin and protein S 100 witch excluded a malignant melanoma or a carcinoma. Death was produced by massive hemoptysis due to pulmonary tuberculosis, manner of death being natural. This is a typical case when preliminary information helps the investigation to define perimeter, organize the personnel, structure the approach and streamlining the efforts as the pathologist is able to advise about the nature of death by interpreting the blood loss as being more likely due to natural disease. Rapidly excluding crime in a large proportion of instances in favor of accident, suicide or natural death is a very useful and cost effective function by disbanding expensive public facilities [3]. Forensic autopsy has a secondary role in terms of epidemiology as the patient didn 't have a history of tuberculosis thus contributing to a more accurate report of morbidity and mortality of the disease. This is relevant from a public health perspective as these institutions rely their strategies and programs on the quality of statistics implicit on the accuracy of death certificate $[4,5]$.

In the second case, there is a man of 58 years old who lived alone in a flat. His daughter was worried because he did not answer the phone so she alerted a neighbor the next day. The neighbor found the man`s body lying on the floor and notified the police. Attended at the scene police contacted the family doctor who agreed to release a medical death certificate, as he was a patient known with arterial hypertension, ischemic stroke, and cirrhosis. Also the patient called the ambulance a few days earlier for an ambulance complaining of pain in the lumbar region. The man`s children however insisted of performing an autopsy as they were suspicious about their father death, claiming to have a dispute over the apartment with his recently divorced wife. Finally the police officer accepted to request a forensic autopsy that was paid by the family. The autopsy performed revealed at external examination two recent bruises located in the anterior cervical region just below the larynx on the right side, of $2.5 / 1.8 \mathrm{~cm}$ and inferior of this of $6 / 4 \mathrm{~cm}$ with hemorrhage in the underlying subcutaneous tissue and muscle at internal examination of the body (Fig. 2). At the autopsy, these findings are difficult to interpret in the absence of elements revealed by death scene investigation, and a sparse history especially when at the scene a superficial external examination omitted to revealed traumatic lesions. Even a detailed history can't duplicate what the eye have seen as subjective influences modify the chosen words.

The autopsy revealed also gross and microscopic nonspecific changes consistent with an asphyxial syndrome and also gross and microscopic expressions of his known pathological conditions. The manner of death was ruled as violent, the cause of death was mechanical asphyxia due to neck compression. In this case the

56 sciendo Journal of Legal Studies Volume 24 Issue 38/2019 ISSN 2457-9017; Online ISSN 2392-7054.

Web: publicatii.uvvg.ro/index.php/jls. Pages $53-62$ 
investigation carried out by police officers relied too much on personal medical history and neglected physical evidence (Fig. 3) and the history of the case, which conducted of failure to detect a suspicious death. In this case co-opting the forensic pathologist in the investigation team could have rise suspicions about the death based on external lesions and target the search toward a possible crime. Conversely there is always the possibility that a suspicious death is not further investigated or when an autopsy is performed some important findings cannot be interpreted in the absence of a relevant data obtained at the scene, especially when the mechanism of death have no specific autopsy findings as in "asphyxic" death and the morphology and topography of lesions is not characteristic. There is also important for the family the doctor who attests the death by filling the death certificate to examine the body even if the police officers were called at the scene. The mission of the doctor who is competent to certify the death is to examine the body to exclude any injury and identify the immediate cause of death. If fail to identify the immediate cause of death of a person with pre-existing conditions, even severe, may mean that the cause of death is unknown and death can have other cause then his known diseases [2].

Notions like "suspect death" or "death of unknown cause" can currently receive different interpretation as these are complex concepts and in absence of a team working together can be used to limit or extend the number of forensic autopsy without scientific reasons. It was to be expected that the changes of criminal law procedures to standardize the investigation of deaths to a certain extend. The investigation of the death scene is a complex process and several teams converge on a scene depending on further investigations needed and scientists and logistic available. Though ideally, the team should include a forensic pathologist, and depending on jurisdiction and manpower there are some areas where the pathologists routinely attend the death scene when conducted, however this is not usually the case in most of the country due to lack of personnel and existing funds. Guidelines for summoning a pathologist to a scene exists in many countries but each death scene is unique and death investigation is "an art that is never mastered" [10] so unfortunately examples of misleading investigation when the pathologist could have advise the investigator with helpful preliminary information are provided in most of the textbooks and other medical literature, though it is hindsight to contemplate what might have happened if the pathologist had been to the scene.

\section{Conclusions}

Death investigation is a complex process that requires much more than just performing an autopsy, investigation of the scene being a crucial part and vital to final ruling as to the cause and manner of death. The death scene investigation may 
Crișan, C., (2019)

The significance of death-scene investigation in determining cause and circumstances of medico-legal death

be as or even more important than the autopsy itself in providing clues about the cause and circumstances of death.

These two cases illustrate just a part of the role of forensic pathologist at the scene death but are sufficient to fully justify the importance of this investigation as no example can comprise the complexity of problems and the particularity of each case, nor a statistic can be made.

The forensic pathologist can assist in making a fair screening of medicolegal cases and by collecting data about medical history, other documents or records, evaluating the circumstances of death, etc. can obtain valuable clues about the cause of death and important aspects and direct further ancillary investigations.

New regulations of law make a framework regarding death investigations, but further guidelines are needed for a homogeneous investigation and for defining the attributions of team members to provide a practice standard. Recommendation No. $\mathrm{R}$ (99) 3 of Council of Europe is trying to harmonize the medicolegal activity between the member states in order to achieve a greater unity and recommends adopting internal standards of quality.

At the death scene the pathologist can evaluate the medical history of the patient with help in interpreting the cause and mechanism of death and the contribution in selecting the medicolegal cases will exempt the family doctor to certify death insufficiently documented. As a consequence the quality of data reported in the death certificate will increase, with impact from public health perspective.

\section{Acknowledgements}

The author thanks the anonymous reviewers and editor for their valuable contribution.

\section{Funding}

This research received no specific grant from any funding agency in the public, commercial, or not - for - profit sectors.

\section{Author Contributions}

The entire article was written by Corina Crișan.

\section{Disclosure Statement}

The authors have not any competing financial, professional, or personal interests from other parties.

\section{References}

1. Belis, V. et al., Tratat de Medicina Legală. s.l., Editura Medicală, Bucureşti, 1995, p.162-166.

58 sciendo Journal of Legal Studies Volume 24 Issue 38/2019 ISSN 2457-9017; Online ISSN 2392-7054.

Web: publicatii.uvvg.ro/index.php/jls. Pages $53-62$ 
Crişan, C., (2019)

The significance of death-scene investigation in determining cause and circumstances of medico-legal death

2. Curcă, G.C., Manualul constatării şi certificării decesului, Ed. Universitară, Bucureşti, 2008, p. 89-95.

3. Dolinak, D., Forensic Pathology: Principles and Practice, Academic Press, 2005.

4. Hanzlick, R., Medical examiners, coroners, and public health: a review and update, Arch Pathol Lab Med, 2006 Sep, 130(9): 1274-82.

5. Hanzlick, R.L., Parrish, R.G., Epidemiologic aspects of forensic pathology, Clin Lab Med, 1998 Mar, 18(1), 23-37.

6. Moritz, A.R., Classical mistakes in forensic pathology. s.1.: American Journal of Clinical Pathology, 1956.

7. Olteanu, G.I., Consideraţii cu privire la tactica efectuării cercetării la faţa locului. s.1.: AIT Laboratories, 2004.

8. Payne-James J., Byard R., Corey T., Henderson C., Encyclopedia of Forensic and Legal Medicine. s.1.: Academic Press, 2005.

9. Peschel, O., Graw, M., Inspection of corpse by the family physician (general practitioner) in practice and nursing home, MMW Fortschr Med 2005 May 12; 147(19): 36-9.

10. Scott, W.A., Death Scene Investigation: A Field Guide. s.1.: CRC Press, 2008.

11. *** Codul de Procedura Penală

12. ***http://www.arad.insse.ro/wp-content/uploads/2019/03/POP107A_ar.pdf

\section{Appendix}

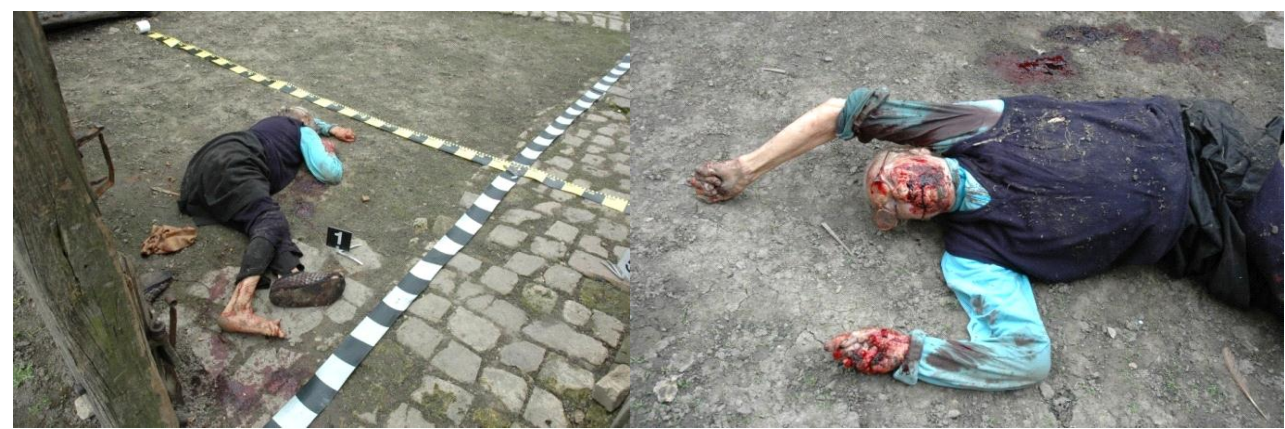

Figure 1 Aspects from death scene investigation. Blood clot in nasal cavity with traces of blood on the face, hands, feet and shoes. 
sciendo

Crişan, C., (2019)

The significance of death-scene investigation in determining cause and circumstances of medico-legal death

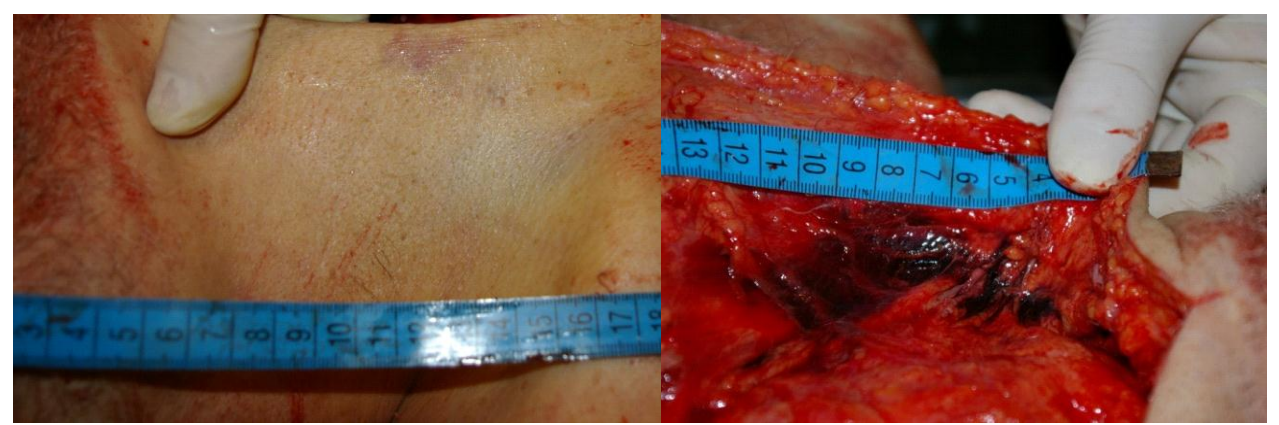

Figure 2 Bruises on anterior region of the neck with hemorrhagic infiltrates in subcutaneous tissue.

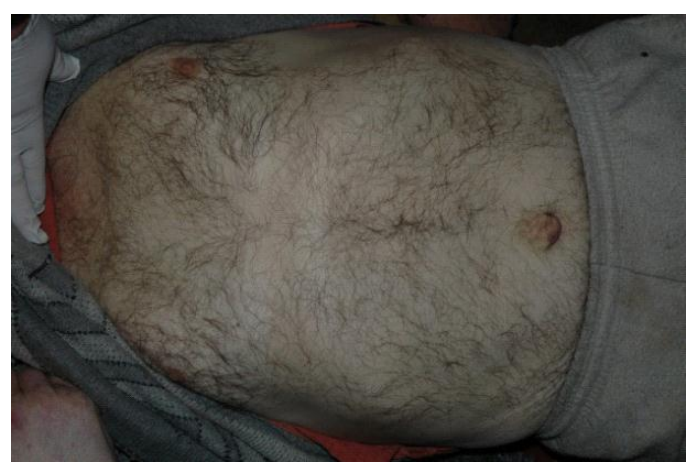

Figure 3 Aspects from death scene investigation. 
The significance of death-scene investigation in determining cause and circumstances of medico-legal death
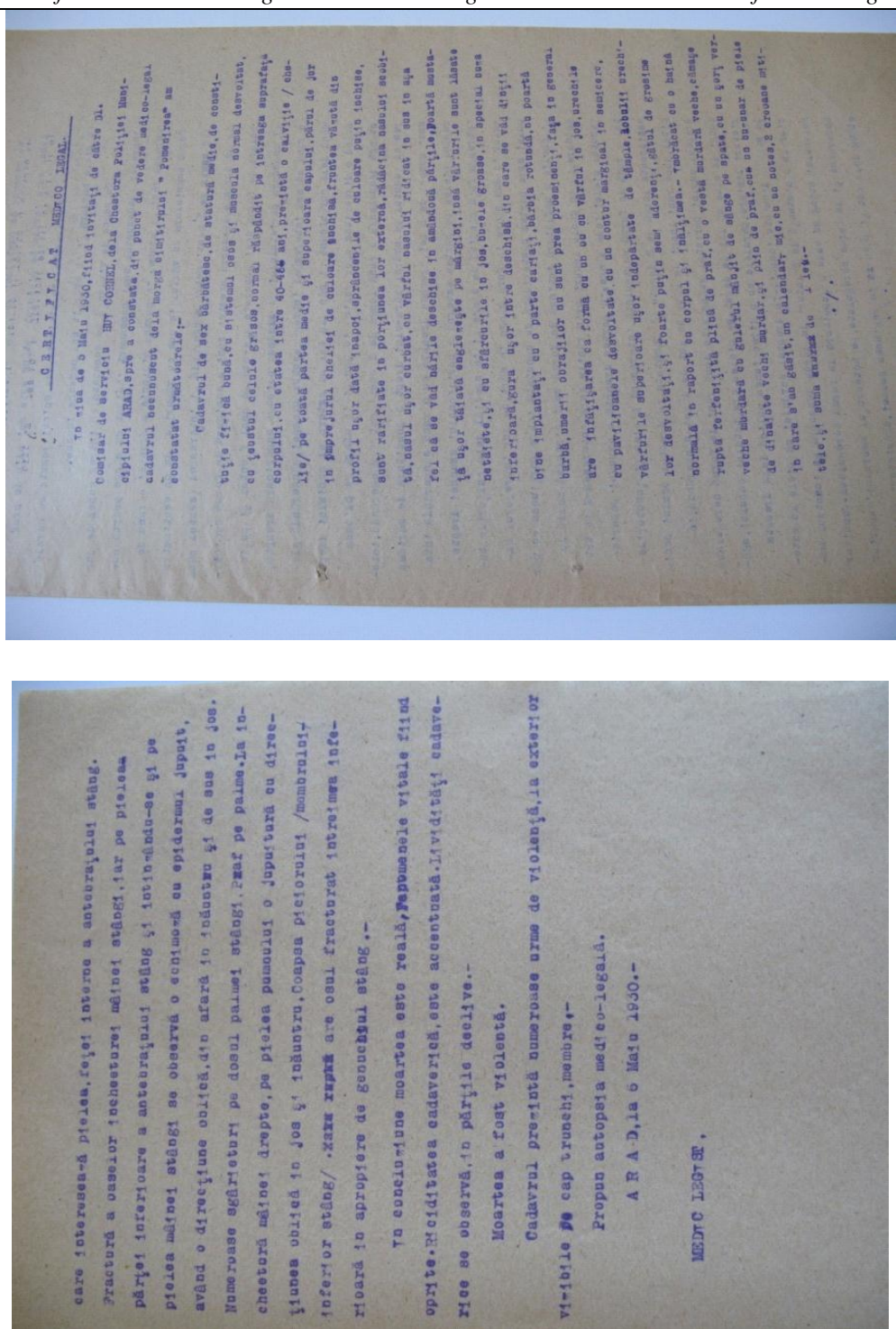

Figure 4 Preliminary conclusions after a death scene investigation. Archive of Legal Medicine Department Arad 1930.

Journal of Legal Studies Volume 24 Issue 38/2019

ISSN 2457-9017; Online ISSN 2392-7054. 


\section{sciendo}

Crișan, C., (2019)

The significance of death-scene investigation in determining cause and circumstances of medico-legal death
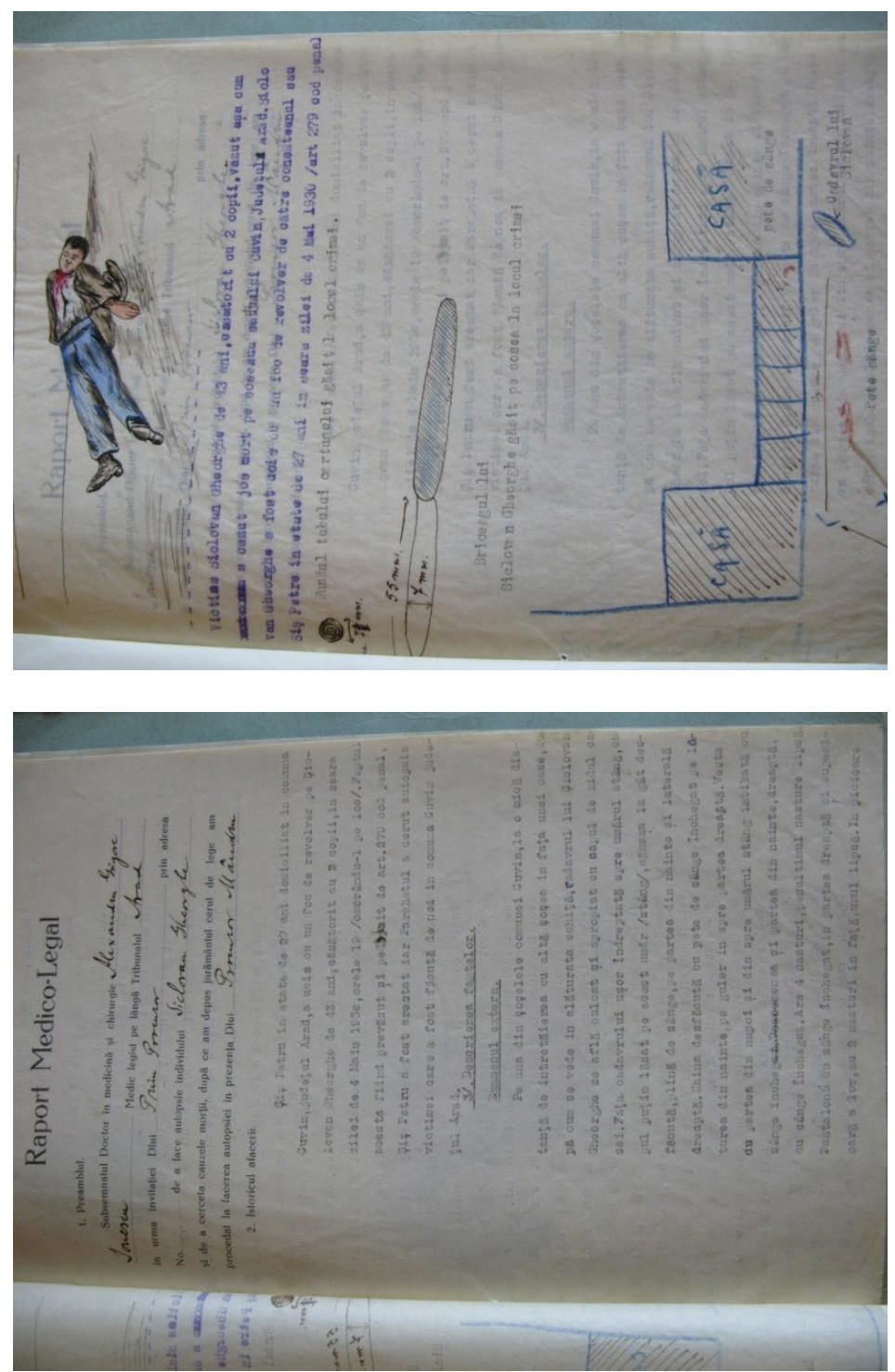

Figure 5 Pictures of death scene investigation and autopsy report (aspects) from a homicide - cervical gunshot wound. 1930 archive of Arad Medico-Legal Department

sciendo Journal of Legal Studies Volume 24 Issue 38/2019

ISSN 2457-9017; Online ISSN 2392-7054.

Web: publicatii.uvvg.ro/index.php/jls. Pages $53-62$ 